\title{
Strategy Implementation and Performance of the Law Courts in Meru County, Kenya
}

\author{
Joseph Kaberia Isaac ${ }^{1}$, Clement Nkaabu ${ }^{2}$, Wilson Muema ${ }^{3}$ \\ ${ }^{1}$ A Master Student, Department of Business Administration, Kenya Methodist University \\ ${ }^{2}$ Lecturer and Director, Department of Business Administration, Kenya Methodist University, Meru Town \\ Campus. \\ ${ }^{3}$ Lecturer and Campus Advisor Coordinator, Kenya Methodist University Main Campus
}

\begin{abstract}
Most organizations, whether private or public have come up with strategic plans in order to successfully attain organizational objectives. Some researchers have noted that organizations do not fully implement their strategic plans within the targeted duration. This study sought to determine factors influencing implementation of strategic plans more so the relationship between strategy implementation and performance in the Kenyan judiciary. Specifically, the study sought to find out how infrastructure affect implementation of strategic plans in the Kenya judiciary. The study used descriptive survey. A descriptive study is one in which information is collected without changing the environment. Stratified sampling was used to identify various strata in the population and simple random sampling was used to obtain the sample of the respondents from the target population of 146 employees of the judiciary. The identified strata 107 consisted of Judges, Magistrates, Executive Officers, Court clerks and Clerical staff. Data for the study was collected using a questionnaire because it is simple to administer and collect large amount of data. Data was analyzed using descriptive statistics and multiple linear regression. Multiple linear regression was used to analyze the data to determine the degree of relationship between the variables under study. All hypotheses were tested using multiple linear regression at 5\% level of significance. Analyzed data was presented in frequency tables, charts and graphs. The study recommends that the judiciary should employ enough personnel especially the judges and magistrates to clear the backlog of cases.
\end{abstract}

Key Words: Strategic planning, Organizational structure, Strategy implementation, National Council on Administration of Justice

\section{Introduction}

Strategic Planning is one of the fundamentals of modern life the world over. Planning, essentially, is the organization of a series of actions to achieve a specified outcome.Strategic planning, has, since the early 1960s, evolved to become one of the essentials of modern business and organizational life. Strategic planning helps determine the direction and scope of an organization over the long term, matching its resources to its changing environment and, in particular, its markets, customers and clients, so as to meet stakeholder expectations (Johnson and Scholes, 2007). Strategic planning is a systematic process of envisioning a desired future, and translating this vision into broadly defined goals or objectives and a sequence of steps to achieve them.

Strategic planning is an organization's process of defining its strategy, or direction, and making decisions on allocating its resources to pursue this strategy. It may also extend to control mechanisms for guiding on the implementation of the strategy. Strategic planning became prominent in corporations during the 1960s and remains an important aspect of strategic management. It is executed by strategic planners or strategists, who involve many parties and research sources in their analysis of the organization and its relationship to the environment in which it competes (Bradford, 2000).

Judiciary globally has been organizing and reorganizing itself for example the judiciary of the United Kingdom which comprise three legal systems found in England and Wales, Northern Ireland and Scotland. However, the judges of the Supreme Court of the United Kingdom, the Special Immigration Appeals Commission, Employment Tribunals, Employment Appeal Tribunal and the UK tribunals system do have a United Kingdom-wide jurisdiction (Glenn and Patrick ,2000). The judges of the Supreme Court of the United Kingdom are known as Justices of the Supreme Court, and they are also Privy Counsellors. Justices of the Supreme Court are granted the courtesy title Lord or Lady for life. The Supreme Court is a relatively new Court being established in October 2009 following the Constitutional Reform Act (2005).

The Judiciary of Kenya is the system of courts that interprets and applies the law in Kenya. After the promulgation of the constitution of Kenya 2010 the general public through parliament sought to reform the judiciary. The Judiciary of Kenya consists of Superior courts made up of the Supreme Court, Courts of Appeal, High Court, Industrial Court, Environment and Land Court, the subordinate courts consisting of Magistrates 
Courts, Courts Martial and Kadhi Courts (Republic of Kenya, 2010). The Supreme Court is the highest court in Kenya, and all other courts are bound by its decisions. It was established under Article 163 of the Constitution of Kenya is the final arbiter and interpreter of the Constitution. The chief administrator of the Supreme Court is the Chief Justice, who is also the president of the Supreme Court. One of his responsibilities is to come up with procedures for running the courts, as well as decisions on staffing and where new courts should be established. Certain situations dictate that the Chief Justice appoints a judge or panel of judges to deal with a specific matter. The Deputy Chief Justice is the deputy president of the Supreme Court (Republic of Kenya, 2010). The Kenya Vision 2030 aims at creating a globally competitive and prosperous country and transforming Kenya into a newly industrialized middle income economy. The Vision is anchored on three key interdependent pillars namely: Economic, Social and political. (Republic of Kenya, 2010).

\section{Statement of the Problem}

Implementation of the strategic plan in the judiciary has become critical in delivery of quality service to Kenyans seeking justice in Law courts. Strategic plan implementation has a considerable influence on performance in the Judiciary although it is affected by multiple factors due to the fact that strategic plans implementation in the judiciary is at its infancy stages. The successful implementation of strategic plans depends not only on the adequacy of the infrastructure, speedy disposal of cases and number of people seeking justice but also on the availability and efficient utilization of resources for effective performance.

The judiciary like any other arm of the government is going through profound changes. With the founding of the Kenya vision 2030, it is important to align the judiciary strategic thinking to the aforesaid vision for good governance and the attainment of Kenya as a middle income economy. The strategic plan for the period 2014-2018 provides the judiciary with strategic direction towards being an example of the best in Africa as well as setting the highest standards of performance in the delivery of quality justice. Each strategic plan has particular merits that are related to the external environment and internal process. Strategy evaluation is used to judge the success of strategy on performance.

Strategy implementation faces a number of challenges which have a bearing on performance. It appears that only less than $30 \%$ of the strategies developed are implemented satisfactorily (Nunally, 2010). Despite the Kenyan judiciary having strategic plans in place from the year 2012, to date no studies has been carried out in the judiciary to assess the effects of strategy implementation has on performance. This study is aimed at assessing how strategic plans implementation has affected performance in the Judiciary. Specifically the study will assess the effects of strategy implementation on infrastructure on performance in the Judiciary.

\section{Objectives of the Study}

\section{General Objective}

The general objective of this study is to determine the relationship between strategic plan implementation and performance of the Kenyan judiciary.

Specific Objectives

i) To assess role of infrastructure during strategy implementation and the performance of the law courts in the Kenyan judiciary.

\section{Research Hypothesis}

$\mathbf{H}_{1}$ : There is statistically significant positive relationship between infrastructure and performance of the law courts in Meru County.

\section{Significance of the Study}

The findings of the study may benefit other strategic plan implementers in other Counties, who will learn from the findings of this study and mirror their operations as per the recommendations of this study.

Scope of the Study

The study was conducted in Meru County law courts, in Kenya. It was conducted during the period of March to October 2016. The judges, Magistrates, Executive Officers, Court Clerks and clerical staff of the Judiciary were the main respondents. The study covered all the Courts stations in Meru County namely: Nkubu, Githongo, Meru, Tigania and Maua law courts.

\section{Assumptions of the Study}

The study assumed that the respondents are knowledgeable on the implementation of Strategic plans and its effects on performance in the Kenyan judiciary. The study also assumed that the respondents filled the questionnaires correctly for effective data collection and analysis.

\section{Limitations of the Study}

The respondents feared disclosing accurate information concerning courts affairs and the fear that the information disclosed could be used by the seniors in victimization. The researcher assured the respondents that the information obtained was to be treated with confidentiality and was to be used for academic purpose only 
Theoretical Review

\section{Review Of Literature}

Theories are formulated to explain, predict, and understand phenomena and, in many cases, to challenge and extend existing knowledge within the limits of critical bounding assumptions. The theoretical framework is the structure that can hold or support a theory of a research study. The literature reviewed for purpose of this study is based on the theory below.

\section{Theory of Reasoned Action}

The Theory of Reasoned Action (TRA), is one of the three classic persuasion models of psychology, and is also used in communication discourse as a theory of understanding persuasive messages. The theory of reasoned action was developed by Martin Fishbein in 1967 and was derived from previous research that began as the theory of attitude. The theory aims to explain the relationship between attitudes and behaviors within human action. TRA is used to predict how individuals will behave based on their pre-existing attitudes and behavioral intentions. An individual's decision to engage in a particular behavior is based on the outcomes the individual expects will come as a result of performing the behavior.

\section{Empirical Review}

The empirical review is based upon strategy implementation respecting infrastructure, organization culture, human resource and communication and public awareness on performance in the Kenyan judiciary.

\section{Role of Infrastructure in Strategic Plan Implementation}

Kenya has embarked on a major transformation of its judicial system to improve key functions to promote better administration of justice and delivery of quality legal services to court users. Kenya's new constitution has created a window of opportunity for the judiciary to address the problems that have for many years frustrated the delivery of justice, especially to the poor (World Bank, 2012).

Through the judicial performance improvement project, the judiciary has started to improve court administration and case management, including automating the courts and clearing the backlog of court cases, training of its judicial officers, and improving court infrastructure by constructing new courts and rehabilitating the existing ones (Republic of Kenya,2012). ICT has been recognized as having an enormous potential to improve the administration of justice as a cross-cutting imperative for the pillars of transformation. Kenyan Judiciary is adopting technology to facilitate speedier trials and enhance the efficiency and effectiveness of administrative performance, (Robison, 2007).

Globalization, population growth, and urbanization are placing considerable strains on infrastructure worldwide. Advanced industrial economies like the United States and Western Europe are focusing on repair and replacement of their aging infrastructures.

\section{Theoretical Framework}

A theoretical framework is a structure that support a theory of research under a study. This section summarizes the theory that have been reviewed for this study. The theory reviewed in this study is: The theory of reasoned action suggests that stronger intentions lead to increased effort to perform the behavior which accelerates the chances of the behavior performed which is a key component of human resource in almost all the organizations. This theory aims at explaining the relationship between attitude and performance in strategy implementation

\section{Conceptual Framework}

The conceptual framework is based on factors influencing various strategy implementation actions on the overall success of strategic plan implementation. The dependent variable is Performance of the law courts. The strategic plan implementation can be affected by number of independent variables which include infrastructure.

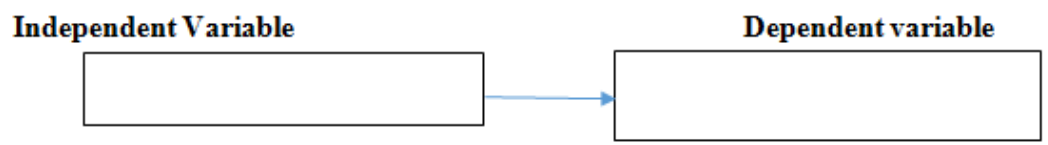

\section{The Conceptual Frame Work}

\section{Explanation of the Independent Variable}

This is an underlying base or foundation especially of an organization, institution or system. Infrastructure are basic facilities, services, and installations needed for the functioning of an institution, such as transportation and communications systems, water and power lines, and public institutions including courts and prisons. 
Infrastructure in the study is concerned with adequacy, availability, suitability, accessibility among other functions of human capacity and capability.

\section{Research Methodology}

\section{Introduction}

This chapter introduces detailed description of the research methodology which was used in this research study to meet the study objectives. Methodology is a detailed procedure used to seek answers to the research questions.

\section{Research Design}

The study adopted descriptive and correlational research designs. Descriptive research design was chosen for the study because information was collected without manipulating the environment, and it provided information about naturally occurring behavior, attitudes and other characteristics of interest of a particular group. Descriptive research design also demonstrates the relationship between the variables under the study.

\section{Target Population}

The units of study are the five law courts situated in Meru County. The target population for the study was 146 employees working in Law courts based in Meru County.

\section{Sample Size and Sampling Procedures}

The sample for this study consisted of 107 respondents selected from 146 employees of the five Law courts. This number was chosen according to Yamane formulae developed in 1967 for determining sample size for small samples. Below is the formulae which was used to get the target population.

$$
\mathrm{n}=
$$

$$
\frac{\mathrm{N}}{1+\mathrm{N}(\mathrm{e})^{2}}
$$

\section{Data Collection Tools}

Questionnaires were used as the main tools for collecting data. The selection of the questionnaire was guided by the nature of the data to be collected, objectives of the study and the time available to undertake the study. The overall aim of this study was to collect data on effects strategic plans have on performance in the judiciary.

\section{Reliability Analysis}

Reliability was increased by testing a diverse sample of individuals and using uniform testing procedures. Cronbach's alpha was used as a lower bound estimate of the reliability of a psychometric test. It has been proposed that alpha can be viewed as the expected correlation of two tests that measure the same construct.

Data Analysis and Presentation

Data for the study was collected using questionnaires and analyzed using descriptive and inferential statistics. Descriptive statistics are used to describe the basic features of the data in a study. Descriptive statistics involved the use frequencies, percentages and cross tabulations.

\section{Data Analysis, Presentation And Interpretation}

\section{Reliability Analysis}

Cronbach alpha was used in the study to ensure the instrument used was reliable.

Cronbach alpha is the most common used to test the reliability coefficient. Alpha is the expected correlation of two tests that measures the same construct.

\section{Questionnaire Response Rate}

A total of 107 questionnaires were administered to the judicial working staff within the five law court stations in Meru County and 98 questionnaires were returned for analysis. A response rate of $91.6 \%$ was obtained and according to Mugenda \& Mugenda, (2008) a response rate of 50\%

\section{Demographic Characteristics}

This section sought to find out the demographic information concerning the respondents. This was aimed at determining whether employees are knowledgeable on strategic plans in the judiciary and its influence on performance and find out the influence of each study variable on performance in the judiciary. The demographic variables under study were the respondent's age, gender, and the level of education, and work experience.

\section{Gender of the Respondents}

From the findings it was established that majority of the respondents $52 \%$ were males while $48 \%$ were females. The result shows that there is almost equal representation of both gender in the employment of judicial staff in Meru County law courts. This means that employment in the judiciary adheres to one third gender rule as provided for by the 2010 constitution (CoK, 2010).

\section{Age of the Respondents}

From the findings it was established that most of the respondents 35\% were aged between 36-45 years, 32.7\% were aged between 26-35years, $11.2 \%$ were between 46-55 years, another $11.2 \%$ were aged over 55 years 
while a paltry $9.2 \%$ were aged 25 years and below. This result indicate that all the age groups are fairly represented in the judiciary work force.

Level of Education

The respondents were asked to state their highest academic qualifications. The respondent's level of education was significant for this study because it would help the researcher to know whether the respondents understood whether judiciary had strategic plans and its significance on performance of the judiciary.

\section{Academic Qualifications}

From the findings it was established that, a majority of the respondents $51 \%$ had Diploma qualifications, $15.3 \%$ had a certificate, $13.3 \%$ had bachelor's degrees, $11.2 \%$ were Form four certificate holders, and $5.1 \%$ had a post graduate degrees while a paltry $4.1 \%$ were KCPE certificate holders. This result indicates that more than half of the respondents had Diploma qualifications and above. This is an indication that the judiciary has an educated work force necessary to offer quality service to Kenyans and implement the strategic plans in the Judiciary.

\section{Experience of the Respondents}

From the data collected it was established that majority of the respondents $40.8 \%$ had an experience of less than 10 years of service, $32.7 \%$ had between $11-20$ years working experience while $14.2 \%$ had an experience of over 30 years, $10.2 \%$ had between $30-40$ years while a paltry $2 \%$ had over 40 years working in the judiciary.The result indicates that all the respondents had reasonable working experience in the judiciary to give their views on strategy implementation and performance in the judiciary. It is worthwhile to note that the strategic plans were introduced in the judiciary in the year 2012. Since all the respondents had at least some years of work experience and majority being graduates, they had reasonable know how to give meaningful opinion on strategy implementation and its effects on performance in the Kenyan judiciary. This shows that the literacy levels of the judicial staff is adequate to help in implementation of the strategic plan and assess its effect on performance.

\section{Infrastructure}

Infrastructure is nowadays viewed as an organizational core necessity for the organizations to survive and prosper in a fast changing competitive business environment. Corporations now use infrastructure such as information technology to gain competitive advantage (Srinivas R. Kandula,2004), to improve customer service delivery and enhance product and service quality (Byrd and Turner,2000). Infrastructure plays a key role in strategy implementation process. Adequate infrastructure improves organizational performance and competitiveness by elimination of duplication of roles (Armstrong Michael, 2000), the researcher wanted to determine the role of infrastructure on strategy implementation and performance in the Kenyan judiciary.

\section{Descriptive Statistics on Infrastructure}

The respondents were asked a number of questions concerning infrastructure in their work stations. On infrastructure the researcher wanted to know whether the judiciary had set up enough courts stations in Meru County. From the findings, $54.1 \%$ of the respondents agreed that Meru County has enough courts stations to serve the members of the public living within Meru and the neighboring Counties. However, $45.7 \%$ of the respondents were of the view that the courts in Meru are not enough.

The respondents were asked to state whether there are enough court rooms in their work stations. From the findings it was established that the court rooms are not enough to serve people seeking justice in courts, with $79.5 \%$ of the respondents indicating absence of adequate rooms and a paltry $20.5 \%$ agreeing there is adequate rooms for rooms to carry their daily duties.

On adequacy of space for maximum efficiency the researcher sought respondents view, a majority 79.6 $\%$ were of the view that the space allocated was not enough for them to perform their daily duties effectively. Only $20.4 \%$ of the respondents said there is no congestion in their working areas. Therefore there is a need to create more space in courts stations in Meru County so that judicial officers can perform their daily chores with maximum efficiency.

The respondents were asked whether renovation done in courts stations in Meru law courts and whether renovation carried out is done to the required standards that befits our judiciary. A majority $72.5 \%$ said renovation is not done regularly to improve the existing facilities while $27.5 \%$ said it is done. Concerning the standard of the renovation $66.3 \%$ said the renovation does not meet the set standards while $33.7 \%$ of the respondent were satisfied with the work done in the judiciary.

The respondents were asked whether there are adequate registries for record keeping and how they are stored because several incidents of courts files going missing have been reported. A majority of the respondents $72.5 \%$ said the registries are not enough to store volumes of documents that are produced in courts. Only a 
paltry $27.5 \%$ of the respondents were satisfied with the law courts registry but when asked whether different registries exist for different cases for easier retrieval, a majority of the respondents $58.2 \%$ were satisfied with the way documents are stored.

\section{Summary of the Findings}

From the findings there is a need to improve the infrastructure in law courts in Meru County ranging from setting up enough court rooms, increasing registries, installing security systems, creating parking space and adopting the use of ICT to improve efficiency and effectiveness of the judicial staff hence increasing performance in the judiciary. These findings agree with the views of Leigh (2008) who observes that adequate infrastructure is essential in working environment to improve service delivery and outcomes. There is need to initiate IT integration in our law courts and the entire judiciary. Providing adequate infrastructure as well as security systems and improving the judicial staff work conditions would help reduce or completely address the continuous accumulation of cases in court hence improving the overall performance of the judiciary.

For successful implementation of strategies which have long term impact on the organization, the support and the performance of employees from all the strata in the organization is inevitable. The human resource role in strategy implementation is considerable (Armstrong, 2000). From the findings it is evident that the number of judges and magistrates are not enough for effective implementation of strategic plans. This is in agreement with Richard K, (2006) who argues that key personnel need to be recruited for effective strategy implementation. According to Weber, Max. (2006), regular promotion and training of employees motivates and equips them with new knowledge and skills to perform effectively. Change management and dispute resolution mechanism were other parameters that were found to significantly influence strategy implementation which is in agreement with Hrebbinak (2008) who argues that disputes resolution mechanisms minimizes conflict among the employees.

The findings further established that the judiciary seems to have redeemed its image. The institution is geared towards dispensing justice to all members of the public irrespective of one status in the society. The judiciary has also opened itself to public scrutiny and encouraged people to seek alternative forms of dispute resolution instead of rushing to courts all the time they have dispute.

\section{Hypothesis Testing}

To determine the factors that are significantly associated with performance in the judiciary a number of hypothesis were formulated and tested at 5\% level of significance using multiple linear regression. These were: There is statistically significant positive relationship between Infrastructure and strategy implementation and performance in the judiciary.

\section{Summary, Conclusions And Recommendations}

\section{Introduction}

The main objective of this study was to examine the strategy implementation and performance of the judiciary. The study variables included infrastructure, human resource, organizational culture and communication and public awareness. The chapter summarizes the findings of the study and highlights conclusion and recommendations made.

\section{Summary of the Findings}

The study found that there was a strong positive correlation between infrastructure and performance in the judiciary as indicated by the beta coefficients and the level of significance. There was enough evidence to support the directional hypothesis that there is a statistically significant positive relationship between infrastructure and performance in the judiciary. This means that an increase in infrastructure provision increases the performance of the judiciary.

\section{Conclusion}

From the study, it can be concluded that there is a need to allocate more resources to the judiciary so that it can be able to carry out its legal mandate. Implementation of strategic plans need to be communicated timely to all the stakeholders. Members of the public must be given an opportunity to participate in implementation of strategic plans during judiciary open days. The second objective was to determine how human resources affect the performance of the judiciary. The results shows that judiciary has a shortage of personnel especially the judges and magistrates. Due to increased level of public awareness and the increased number of people seeking justice in Kenyan courts then, the judiciary need to employ more judges and magistrates to speed up delivery of justice to all irrespective of the status in the society. Regular training, promotion done on merit and constant replacement of judicial officers who leave a station need to be done on regular basis. 
On organizational culture it was noted that judiciary has its organization culture where leadership and team work plays a major role. It was noted that judiciary culture is transformative and easily accommodates change to increase effectiveness and efficiency. It is noteworthy that judiciary upholds the highest ethical and professional standards in this country. Changes in technology has also been found to impact on the organization culture in the judiciary. Finally it is noteworthy that during the open day's public turn in large numbers and members of the public support strategic plans of the judiciary. The judiciary also educates the public on the need to employ alternative dispute resolution mechanisms instead of rushing to court any time a dispute arises. It was also established that public has gained faith in the judiciary after the implementation of various judicial reforms.

\section{Refrences}

[1] Armstrong Michael. (2000). Strategic Human Resource Management: A Guide to Action, 2nd Edition. London: Kogan Page

[2] Glenn, H. Patrick (2000). Legal Traditions of the World. Oxford University Press

[3] Government of Kenya (2012). Development of Education; National Report of Kenya Nairobi: Ministry of Education. 63-112

[4] Hrebiniak, L. (2008) Obstacles of Effective Strategy Implementation: Organizational Dynamics

[5] James, C. (2011) Theory of Change Review: A Report Commissioned by Comic Relief. London: Comic Relief.

[6] Johnson, Rand Scholes, K. (2003).The Financial Times Guide to Strategy, FT Prentice Hall, $3^{\text {rd }}$ edition

[7] Judiciary Transformation Framework (2012-2016), Equitable access to and expeditious Delivery of Justice, Government Printer.

[8] Srinivas R. Kandula. (2004) Research Methodology; Methods and Techniques. New Delhi:New Age International Publishers

[9] Leigh, T. (2008). Contracting for Government Services: Theory and Evidence from U.S. cities

[10] Mugenda, O.M. and Mugenda, A.G (2008). Research Methods: Nairobi Laba Graphics Services

[11] Richard K, (2006).The Financial Times Guide to Strategy, FT Prentice Hall, and 3rd Edition.

[12] Robinson, J.A (2007), Strategic management: formulation, implementation and Control, 10th edition McGraw Hill.

[13] Srinivas R. Kandula. (2004) Strategic Human Resource Development. New Delhi, India: Prentice Hall 